\title{
Effect of a rehabilitation-based chronic disease management program targeting severe COPD exacerbations on readmission patterns
}

This article was published in the following Dove Press journal:

International Journal of COPD

23 August 2017

Number of times this article has been viewed

\author{
C Lalmolda ${ }^{1-3}$ \\ R Coll-Fernández ${ }^{4}$ \\ N Martínez' \\ M Baré ${ }^{5}$ \\ M Teixidó Colet ${ }^{5}$ \\ F Epelde ${ }^{6}$ \\ E Monsól-3

\section{On behalf of the COPD Multidisciplinary Management Group \\ 'Respiratory Diseases Department, Hospital Universitari Parc Tauli, ${ }^{2}$ Ciber de Enfermedades Respiratorias - Ciberes, ${ }^{3}$ Universitat Autònoma de Barcelona - UAB, ${ }^{4}$ Rehabilitation Department, Hospital Universitari Parc Tauli, ${ }^{5}$ Primary Care Unit Vallés Occidental, Institut Català de la Salut, ${ }^{6}$ Short Stay Unit, Emergency Service, Hospital Universitari Parc Taulí, Barcelona, Spain}

Correspondence: E Monsó Respiratory Diseases Department, Hospital Parc Tauli Sabadell, Carrer, Parc Tauli, I, 08208 Sabadell, Barcelona, Spain Email emonso@tauli.cat
Background: Pulmonary rehabilitation (PR) is recommended after a severe COPD exacerbation, but its short- and long-term effects on health care utilization have not been fully established.

Aims: The aims of this study were to evaluate patient compliance with a chronic disease management (CDM) program incorporating home-based exercise training as the main component after a severe COPD exacerbation and to determine its effects on health care utilization in the following year.

Materials and methods: COPD patients with a severe exacerbation were included in a case-cohort study at admission. An intervention group participated in a nurse-supervised CDM program during the 2 months after discharge, comprising of home-based PR with exercise components directly supervised by a physiotherapist, while the remaining patients followed usual care.

Results: Nineteen of the twenty-one participants (90.5\%) were compliant with the CDM program and were compared with 29 usual-care patients. Compliance with the program was associated with statistically significant reductions in admissions due to respiratory disease in the following year (median [interquartile range]: $0[0-1]$ vs $1[0-2.5] ; P=0.022$ ) and in days of admission ( 0 [0-7] vs 7 [0-12]; $P=0.034$ ), and multiple linear regression analysis confirmed the protective effect of the CDM program ( $\beta$ coefficient $-0.785, P=0.014$, and $R^{2}=0.219$ ).

Conclusion: A CDM program incorporating exercise training for COPD patients without limiting comorbidities after a severe exacerbation achieves high compliance and reduces admissions in the year following after the intervention.

Keywords: COPD, chronic disease management, CDM, rehabilitation, exacerbation, admission

\section{Introduction}

COPD has a high prevalence worldwide ${ }^{1}$ and is forecast to be the world's fourth largest cause of mortality by $2030 .^{2}$ COPD exacerbations are characterized by increases in the patient's baseline dyspnea and sputum production and/or the appearance of purulence, which may warrant a change in regular medication, and are associated with a greater probability of recurrence and death. ${ }^{3,4}$ Admissions due to a severe exacerbation are associated with a significant reduction in physical activity ${ }^{5,6}$ and with impaired exercise capacity after discharge, ${ }^{7}$ which may be improved through exercise training. ${ }^{8}$ Pulmonary rehabilitation (PR) increases exercise tolerance in COPD. ${ }^{9,10}$ It has been shown to reduce the use of health care resources ${ }^{11,12}$ and shorten subsequent admissions and hospital stays due to respiratory disease in stable COPD; however, its role in COPD exacerbations is controversial. The current evidence suggests that PR is feasible when introduced immediately after an exacerbation, ${ }^{13}$ and a recent review ${ }^{14}$ concluded that PR following these acute episodes is associated with statistically significant and 
clinically relevant improvements in 6-minute walking test (6MWT) and shuttle test.

The current guidelines consider PR as a safe procedure within 1 month of hospital discharge ${ }^{9}$ and recommend its use in COPD patients, ${ }^{15}$ suggesting that its implementation in this clinical setting requires an interdisciplinary approach combining respiratory medicine, rehabilitation, and social and behavioral sciences and focusing on effective and individualized strategies to improve physical activity. ${ }^{16,17}$ However, the contents of successful PR programs carried out to date have varied widely, ${ }^{18-20}$ and previous reports have identified comorbidities, transport to the rehabilitation center, and schedules as the main obstacles to their implementation. ${ }^{21}$

The aims of this study were to evaluate the compliance with a chronic disease management (CDM) program incorporating home-based PR with exercise training as its main component after a severe exacerbation in a selected population of COPD patients and to determine the effects of this program on health care use the following year, focusing on admissions due to respiratory disease after discharge as primary outcome.

\section{Materials and methods Study design and population}

Determinants of recurrent admission after a severe COPD exacerbation were assessed through a case-cohort study, ${ }^{22}$ nested in an open cohort consisting of all patients admitted to a university hospital from January 2011 to June 2012 for an exacerbation of COPD who reported previous admissions due to the same cause. Patients admitted with this primary diagnosis (ICD9 491.21, 491.22, 492.8, 493.2, and 494.1; or 518.81 and 518.84 , with any of the previous ICD9 categories as a second diagnosis) were identified and included in the cohort, when a diagnosis of COPD had been established according to the American Thoracic Society/ European Respiratory Society guidelines ${ }^{23}$ and based on a spirometry performed the previous year during stability. The inclusion criterion for the case-cohort study was a record of a previous admission for a severe COPD exacerbation during the previous 3 years, registered in any of the hospitals of the region and/or primary card records. Patient frailty, defined as one or more comorbidities limiting cognitive or exercise capabilities, a cluster of $\geq 3$ admissions in the previous year, or an admission lasting over 30 days during the same period were exclusion criteria. Patients under the age of 40, with a lifetime diagnosis of asthma, cystic fibrosis, neoplasia, or bronchiectasis as a primary diagnosis, or those receiving long-term treatment with oral corticosteroids or immunosuppressors were also excluded. Participating patients were enrolled over an 18-month period and were followed for 1 year after enrollment.

Patients included in the case-cohort study were ascribed every day to the intervention or the control groups in accordance with their hour of admission during the 18 months of enrollment. The first admitted patient of the day fulfilling the inclusion criteria for the case-cohort study was invited to participate in the CDM program, while subsequent patients who met the inclusion criteria conformed to the control group and followed usual care. The study was designed to include a minimum of 50 patients, with a minimal recruitment period of 1 year, estimated from the ten percent prevalence of enrollment criteria in COPD exacerbations admitted to the hospital the previous years. The study protocol was approved by the ethics committee of the Hospital Universitari Parc Taulí and an informed consent was given by all participants in the CDM program.

\section{Variables and measurements}

Sociodemographic data were recorded at enrollment by means of a questionnaire that investigated smoking habit, current respiratory symptoms, comorbidities, and previous exacerbations. Lung function values during stability were obtained from the most recent available forced spirometry with reversibility testing performed during the previous year according to standard techniques ${ }^{24}$ with the same dry rolling seal spirometer (Spirometrics, Gray, ME, USA). Forced vital capacity (FVC) and expiratory volume in the first second $\left(\mathrm{FEV}_{1}\right)$ were recorded for the study, and were expressed as postbronchodilator absolute values $(\mathrm{mL})$ and percentages of the reference values, using age- and height-adjusted reference values obtained from selected volunteers from the Barcelona province. ${ }^{25}$

Acute episodes of increased dyspnea and sputum production and/or purulence during the year after discharge were identified as exacerbations ${ }^{26,27}$ and were considered in the present study when treated with antibiotics and/or oral corticosteroids by the attending physician in the primary care setting or at hospital in accordance with the guidelines. ${ }^{28}$ Exacerbations and mortality during the year after enrollment were recorded from hospital and primary care records, and acute episodes were considered as severe when requiring an admission over 24 hours. The number of admissions due to respiratory causes in the year after enrollment was the primary outcome of the study, while days of hospitalization of these admissions and mortality due to any cause were the secondary outcomes. 


\section{Intervention}

As part of usual care, all participants received education on prescribed oral and inhaled treatment and recommendations for physical activity during their admission. Current smokers were referred to a smoking cessation program in accordance with the guidelines. ${ }^{29}$ The CDM program was implemented immediately after discharge by physicians, nurses, and physiotherapists from the hospital and primary care setting. The intervention group followed PR for 2 months immediately after discharge which included exercise training as a main component. The CDM program included nurse supervision of treatment adherence with scheduled monthly calls to check health status and compliance and by unscheduled phone consultations with the nurse when required. The home-based PR followed by the intervention group consisted of an 8-week program directly supervised by a physiotherapist team, which included exercise components previously validated in clinical trials. ${ }^{20,30-32} \mathrm{PR}$ started within 72 hours of hospital discharge and consisted of 1 hour of exercise training at home twice per week for 8 weeks. After the first week of home-based $\mathrm{PR}$, an individualized daily training plan was proposed to the patient, and compliance with this plan was checked in the following sessions by the physiotherapist through a checklist-based interview. Exercise training included respiratory physiotherapy, practice in energy-saving techniques, and endurance and strength exercises for the peripheral muscles. Exercise intensity and duration were gradually increased over time by the physiotherapist on an individualized basis in the presential sessions. After the 2-month scheduled PR at patient's home, compliance with the individualized exercises was supervised every month at follow-up nurse calls during 1 year. Functional capacity was measured in patients in the intervention group through forced spirometry, oxygen saturation, and 6MWT in accordance with the American Thoracic Society guidelines and using standardized instructions and encouragement. ${ }^{33}$ Measurements were performed 48-72 hours after discharge, at the end of PR, and 6 months after enrollment.

\section{Statistical analysis}

Data were analyzed using the SPSS statistical software package version 18 (SPSS Inc., Chicago, IL, USA). Results for categorical variables are expressed as absolute and relative frequencies, and results for continuous variables as means (standard deviation [SD]) or as medians (percentile 25-75 [P25-P75]) when the distribution was not normal. Exacerbations requiring treatment during the year after discharge (both moderate and severe) and mortality in the same period were calculated. Admissions due to a severe COPD exacerbation were considered as the primary outcome and inpatient days due to respiratory disease and mortality due to any cause as the secondary outcomes, so as to determine the protective effect of the program on severe exacerbations.

First, compliance with the CDM program (ie, participation in $>80 \%$ of PR sessions) was determined in participants; second, admission frequencies, inpatient days, and mortality were compared in patients on the program and usual-care patients (chi-square test, Student's $t$-test, and non-parametric test, as required). Finally, univariate and multivariate linear regression analyses were used to analyze the association between independent variables and the main outcome, including all variables showing a significance up to $0.10 \%$ in the models. All analyses were performed including only participants compliant with the CDM program ("pre-protocol"), while a secondary multivariate linear regression analysis was performed in accordance with "intention-to-treat" criteria, including both compliant and non-compliant patients in the intervention group.

\section{Results}

A total of 67 out of 837 severe exacerbations examined during the recruitment period appeared in patients with a previous admission due to acute respiratory disease in the previous 3 years. Fifty of them appeared in COPD patients with clinically significant comorbidities who accomplished the criteria for the present case-cohort study. Twenty-one of these were selected for participation in the CDM program that was accepted by 19 of them (90.5\%), who participated in over $80 \%$ of the scheduled PR sessions. Two patients declined to participate within 2 weeks of enrollment (9.5\%), and hence they were excluded from subsequent "per-protocol" analyses. Participants were compared with the remaining 29 usual-care patients who made up the control group (Figure 1). Patients in intervention and control groups were homogeneous in terms of age, gender, smoking status, comorbidities, lung function, and number of exacerbations in the previous year (Table 1).

Statistically significant improvements in lung volume, oxygen saturation, and exercise capacity were observed 2 months after discharge in participants compliant with the CDM program compared with their values at admission. FVC (\%) increased from 63.1 (SD 15.8) to 71.6 (15.3) $(P=0.018$, Student's $t$-test) and oxygen saturation (\%) from 92 (SD 2) to 95 (SD 1) $(P<0.001$, Student's $t$-test). Similarly, 6MWT improved from 278.9 (SD 89.7) to $344.2 \mathrm{~m}$ (SD 59.8) ( $P=0.003$, Student's $t$-test). These improvements were 


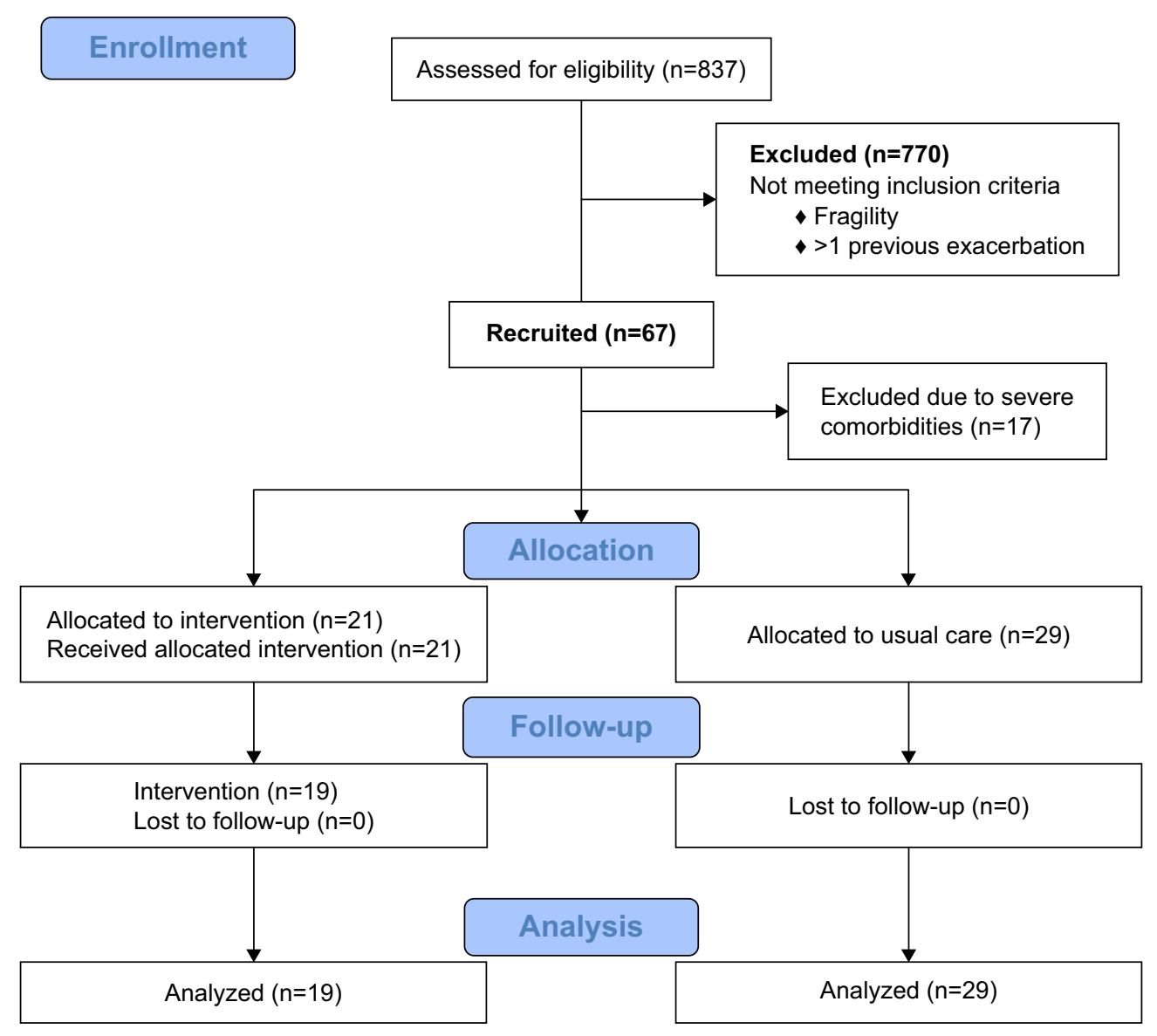

Figure I Enrollment flow diagram.

maintained half a year after the admission. Changes in the other lung function parameters measured did not reach statistical significance.

During the 2 months of follow-up after enrollment, the 19 COPD patients compliant with the CDM program experienced a similar number of exacerbations than the 29 usualcare patients $(P=0.159$, Mann-Whitney $U$-test $)$ and also an equivalent number of admissions $(P=0.741$, Mann-Whitney

Table I Baseline characteristics: patients in chronic disease management (CDM) program and usual-care patients $(n=48)$

\begin{tabular}{llll}
\hline & $\begin{array}{l}\text { CDM } \\
\text { program }^{\text {a }}\end{array}$ & $\begin{array}{l}\text { Usual- } \\
\text { care }\end{array}$ & P-value \\
\hline $\mathrm{N}$ & 19 & 29 & - \\
Age (years; mean [SD]) & $74.3(7.6)$ & $71.4(6.8)$ & 0.182 \\
Gender (women; n [\%]) & $\mathrm{I}(5.3)$ & $2(6.9)$ & 1.000 \\
Current smoking, n (\%) & $4(21.1)$ & $4(13.8)$ & 0.695 \\
Charlson index, median (IQR) & $2(1-3)$ & $2(1-3)$ & 0.816 \\
Postbronchodilator FEV,\%, mean (SD) & $46.7(10.6)$ & $45.4(14.7)$ & 0.740 \\
Severe exacerbations previous year, & $0(0-1)$ & $\mathrm{I}(0-1)$ & 0.400 \\
median (IQR) & & & \\
\hline
\end{tabular}

Note: ancluding only patients compliant with the CDM.

Abbreviations: $\mathrm{FEV}_{1}$, expiratory volume in the first second; IQR, interquartile range.
$U$-test) (Table 2). Patients following the program and those with usual care also experienced a similar number of exacerbations when considering the whole year after enrollment (median 2 [interquartile range 1-5] vs 3 [1-5], respectively, $P=0.166$, Mann-Whitney $U$-test), but participants compliant with the CDM program had fewer admissions due to severe exacerbation ( 0 [0-1] vs 1 [0-2.5], $P=0.022$, Mann-Whitney $U$-test) and spent fewer days in hospital ( 0 [0-7] vs 7 [0-12], $P=0.034$, Mann-Whitney $U$-test). Mortality in the year after enrollment was below $10 \%$ in both groups and there were no statistically significant differences between them (Table 2).

In the regression analyses, compliance with the CDM program was inversely associated with the number of admissions due to respiratory disease in the year after enrollment $(P=0.014)$, together with postbronchodilator $\mathrm{FEV}_{1} \%$ $(P=0.025)$. Multiple linear regression analysis confirmed both predictors as determinants and the program's protective role against the appearance of severe exacerbations during follow-up, since the greater part of the variance in this outcome in the multivariate model was explained by the participation in the program $\left(R^{2}=0.219\right)$ (Table 3$)$. 
Table 2 Exacerbations and mortality 2 and 12 months after enrollment $(n=48)$

\begin{tabular}{|c|c|c|c|c|c|c|}
\hline & \multicolumn{3}{|l|}{2 months } & \multicolumn{3}{|l|}{12 months } \\
\hline & $\begin{array}{l}\text { CDM } \\
\text { program }^{\mathrm{a}}\end{array}$ & $\begin{array}{l}\text { Usual- } \\
\text { care }\end{array}$ & $P$-value & $\begin{array}{l}\text { CDM } \\
\text { program }^{\mathrm{a}}\end{array}$ & $\begin{array}{l}\text { Usual- } \\
\text { care }\end{array}$ & $P$-value \\
\hline$N$ & 19 & 29 & - & 19 & 29 & - \\
\hline Exacerbations $^{\mathrm{b}} \geq \mathrm{I}, \mathrm{n}(\%)$ & $2(10.5)$ & $8(27.6)$ & - & $8(27.5)$ & $25(86.2)$ & - \\
\hline Exacerbations $^{\mathrm{b}}$ median (IQR) & $0(0-0)$ & $0(0-0)$ & 0.159 & $2(I-5)$ & $3(I-5)$ & 0.166 \\
\hline Admissions $^{c} \geq \mathrm{I}, \mathrm{n}(\%)$ & $2(10.5)$ & $4(13.8)$ & - & $7(36.8)$ & $19(65.5)$ & - \\
\hline Admissions ${ }^{c}$ median (IQR) & $0(0-0)$ & $0(0-0)$ & $0.74 I$ & $0(0-1)$ & $\mathrm{I}(0-2.5)$ & 0.022 \\
\hline Inpatient days ${ }^{\mathrm{c}}$ median (IQR) & $0(0-0)$ & $0(0-0)$ & 0.595 & $0(0-7)$ & $7(0-12)$ & 0.034 \\
\hline Mortality ${ }^{d}(\%)$ & - & - & - & $0(0)$ & $2(6.9)$ & 0.512 \\
\hline
\end{tabular}

Notes: ancluding patients compliant with the CDM program; btreated with antibiotics and/or corticosteroids; 'due to respiratory disease; dany cause.

Abbreviations: CDM, chronic disease management; IQR, interquartile range.

The CDM program attained similar results when considering the number of inpatient days due to respiratory disease 2 months and 1 year after enrollment, after adjustment for covariates ( $P=0.595$ and $P=0.034$, respectively). The significance of the relationships between the program and the number of severe exacerbations and inpatient days was lost in the multiple regression analyses when both compliant and non-compliant patients in the intervention group were considered, in accordance with "intention-to-treat criteria" ( $P=0.262$ and $P=0.125$, respectively).

\section{Discussion}

In the present study, compliance with a CDM program that included exercise training as a main component was above $90 \%$ when targeting severe COPD exacerbation patients who had one previous admission for respiratory disease and had no limiting comorbidities. In this selected group of patients, the program was unable to reduce short-term readmissions after discharge, but it did achieve a statistically significant decrease in severe exacerbations the following year, paralleled by an equivalent decrease in the number of inpatient days due to respiratory disease.

The CDM program implemented after an admission due to COPD exacerbation and incorporating PR as its main component reduced severe exacerbations in the year after the intervention. In stable COPD patients, $\mathrm{PR}$ programs have shown their ability to minimize subsequent admissions and are recommended in the current guidelines, ${ }^{9}$ and they also improve exercise capacity in COPD patients after an admission for respiratory causes. ${ }^{8,9,31,34-36} \mathrm{PR}$ during admission has not shown a significant effect on the frequency of readmission within a year, ${ }^{37}$ and when implemented after discharge, it does not consistently prevent short-term readmissions, ${ }^{18,20,32,38-40}$ but exercise training has been reported to reduce readmissions within a year of a severe exacerbation in some clinical trials $^{30,41}$ and systematic reviews. ${ }^{40,42}$ In our study, PR with two weekly sessions of exercise training for 8 weeks scheduled after an admission did not prevent short-term readmissions, but it achieved a statistically significant reduction of severe exacerbations the year after discharge without affecting the frequency of exacerbations as a whole. This finding supports the hypothesis that exercise training reduces the severity of exacerbations and the need for hospital admissions, an effect that only becomes evident after the completion of the 2-month rehabilitation program.

Integrated management programs including two or more interventions in COPD patients administered at two or more health care levels have been assessed in a variety of clinical

Table 3 Univariate and multivariate analyses of predictors of admissions 2 and 12 months after discharge $(n=48)$

\begin{tabular}{|c|c|c|c|c|c|c|c|c|c|}
\hline & \multicolumn{3}{|c|}{$\begin{array}{l}\text { Univariate linear regression } \\
\text { ( } 2 \text { months) }\end{array}$} & \multicolumn{3}{|c|}{$\begin{array}{l}\text { Univariate linear regression } \\
\text { ( } 12 \text { months) }\end{array}$} & \multicolumn{3}{|c|}{$\begin{array}{l}\text { Multivariate linear regression } \\
\text { (1 } 2 \text { months) }\end{array}$} \\
\hline & $\beta$ & $95 \% \mathrm{Cl}$ & P-value & $\beta$ & $95 \% \mathrm{Cl}$ & $P$-value & $\beta$ & $95 \% \mathrm{Cl}$ & $P$-value \\
\hline Age & -0.003 & $-0.017 / 0.011$ & 0.665 & -0.025 & $-0.072 / 0.021$ & 0.109 & - & - & - \\
\hline Gender & -0.133 & $-0.537 / 0.270$ & 0.509 & 0.444 & $-0.939 / 1.828$ & 0.521 & - & - & - \\
\hline Current smoking & 0.150 & $-0.110 / 0.410$ & 0.251 & 0.250 & $-0.650 / 1.150$ & 0.579 & - & - & - \\
\hline Charlson comorbidity index & 0.073 & $-0.018 / 0.164$ & 0.112 & -0.036 & $-0.356 / 0.284$ & 0.821 & - & - & - \\
\hline Postbronchodilator $\mathrm{FEV} \%$ & -0.001 & $-0.008 / 0.007$ & 0.835 & -0.323 & $-0.053 /-0.004$ & 0.025 & -0.027 & $-0.050 / 0.004$ & 0.025 \\
\hline CDM program & 0.033 & $-0.168 / 0.233$ & 0.744 & -0.354 & $-1.464 /-0.177$ & 0.014 & -0.785 & $0.170 / 1.401$ & 0.014 \\
\hline
\end{tabular}

Abbreviations: CDM, chronic disease management; $\mathrm{FEV}_{1}$, expiratory volume in the first second. 
settings. ${ }^{43-46}$ These programs have been shown to be safe ${ }^{47}$ and to exert a protective effect against severe exacerbations when they incorporate exercise training. ${ }^{44-46,48}$ Interventions based on self-management alone have not attained equivalent results, with improvements restricted to disease coping and treatment adherence, ${ }^{49-51}$ that are not paralleled by an impact on admissions in the following year, ${ }^{48,51-53}$ with one study even reporting a potential negative effect on survival. ${ }^{50} \mathrm{~A}$ similar lack of effect on subsequent admissions has been reported for telemonitoring interventions ${ }^{54,55}$ and for other outpatient interventions restricted to a single component. ${ }^{56}$ In keeping with previous CDM programs that have demonstrated welldefined effects on subsequent admissions, the intervention carried out in our study was designed to be both multilevel and multicomponent, and included education and nurse-assisted management at hospital and primary care levels, combined with PR at home directly supervised by physiotherapists.

The CDM intervention implemented in the present study attained statistically significant improvements in lung volume, oxygen saturation, and exercise capacity in the patients compared with their discharge values. 6MWT had an average improvement of over $60 \mathrm{~m}$, as has been previously reported with exercise training, ${ }^{8,31}$ surpassing the distance considered as clinically significant. ${ }^{34,57,58}$ This improvement, accordingly, may be ascribed to the rehabilitation component of the CDM program.

The CDM program had a compliance rate of above $90 \%$ for all its components, higher than the previously reported rates. ${ }^{59-61}$ Lack of compliance in exercise training programs has been attributed to transport and scheduling difficulties, comorbidities, and/or a rejection of the hospital setting. ${ }^{60}$ The high compliance rate attained in the present study must be partly related to patient selection, considering that patients with advanced disease, multiple admissions, or clinically significant comorbidities were not considered, and to the inclusion of the PR in an integrated CDM program carried out for the most part in the patient's home. Higher success rates of PR have been previously reported when exercise training has been implemented as part of multicomponent programs involving physicians, nurses, and physiotherapists. ${ }^{43}$

Limitations of the study were, first, the number of patients participating in the case-cohort study, and, second, the design restriction to patients reporting a single previous exacerbation. Accordingly, the positive results of the present study cannot be extrapolated to COPD patients with frequent severe exacerbations who are commonly found as inpatients in most hospitals. Recurrent admissions are often related to comorbidities that limit participation in exercise training and render patients ineligible for PR programs. ${ }^{59}$ Focusing on COPD patients who reported two single severe exacerbations restricts the target to only one tenth of admissions in a general hospital, also, it gives relevance to the study considering that this patient population is easily identifiable, where positive results with CDM programs may be expected.

\section{Conclusion}

In conclusion, a 2-month integrated CDM program including exercise training for COPD patients with a severe exacerbation attained a compliance rate of $90 \%$ and reduced subsequent admissions due to respiratory disease after the end of the intervention. PR as part of a multicomponent CDM program exerts a protective effect on recurrent admissions in COPD patients who do not have either limiting comorbidities or multiple admissions.

\section{Acknowledgments}

We thank Michael Maudsley for providing an outline for this manuscript and support in editing and journal styling. The study has been a proposal of Pla Director de Malalties Respiratòries-Generalitat de Catalunya, and funded by Sociedad Española de Neumología y Cirugía Torácica-SEPAR, BRN-Ramon Pla Armengol Foundation and an AstraZeneca unrestricted grant.

On behalf of the COPD Multidisciplinary Management Group: Servei de Pneumologia, Hospital Universitari Parc Taulí (C Lalmolda, N Martinez, M Arranz, and E Monsó [coordinator]); Servei de Rehabilitació, Hospital Universitari Parc Taulí (R Coll-Fernandez, H Prados, J Estela, C Pozo); Servei d'Atenció Primària Vallés Occidental, Institut Català de la Salut (M Bare, M Teixido, O Sanchez, E Jaimez); Servei d'Urgències, Hospital Universitari Parc Taulí (F Epelde).

\section{Disclosure}

The authors report no conflicts of interest in this work.

\section{References}

1. Buist AS, McBurnie MA, Vollmer WM, et al. International variation in the prevalence of COPD (the BOLD Study): a population-based prevalence study. Lancet. 2007;370(9589):741-750.

2. Mathers CD, Loncar D. Projections of global mortality and burden of disease from 2002 to 2030. PLoS Med. 2006;3(11):e442.

3. Suissa S, Dell'Aniello S, Ernst P. Long-term natural history of chronic obstructive pulmonary disease: severe exacerbations and mortality. Thorax. 2012;67(11):957-963.

4. Groenewegen KH, Schols AM, Wouters EF. Mortality and mortalityrelated factors after hospitalization for acute exacerbation of COPD. Chest. 2003;124(2):459-467.

5. Esteban C, Quintana JM, Garcia-Gutierrez S, et al. Determinants of change in physical activity during moderate-to-severe COPD exacerbation. Int J Chron Obstruct Pulmon Dis. 2016;11:251-261. 
6. Pitta F, Troosters T, Probst VS, Spruit MA, Decramer M, Gosselink R. Physical activity and hospitalization for exacerbation of COPD. Chest. 2006;129(3):536-544.

7. Ramon MA, Gimeno-Santos E, Ferrer J, et al. Hospital admissions and exercise capacity decline in patients with COPD. Eur Respir J. 2014; 43(4):1018-1027.

8. Kirsten DK, Taube C, Lehnigk B, Jörres RA, Magnussen H. Exercise training improves recovery in patients with COPD after an acute exacerbation. Respir Med. 1998;92(10):1191-1198.

9. Spruit MA, Singh SJ, Garvey C, et al; ATS/ERS Task Force on Pulmonary Rehabiliation. An official American Thoracic Society/European Respiratory Society statement: key concepts and advances in pulmonary rehabilitation. Am J Respir Crit Care Med. 2013;188(8):e13-e64.

10. Ries AL, Bauldoff GS, Carlin BW, et al. Pulmonary rehabilitation: joint ACCP/AACVPR evidence-based clinical practice guidelines. Chest. 2007;131(5 Suppl):4S-42S.

11. Troosters T, Casaburi R, Gosselink R, Decramer M. Pulmonary rehabilitation in chronic obstructive pulmonary disease. Am J Respir Crit Care Med. 2005;172(1):19-38.

12. Lacasse Y, Goldstein R, Lasserson TJ, Martin S. Pulmonary rehabilitation for chronic obstructive pulmonary disease. Cochrane Database Syst Rev. 2006;(4):CD003793.

13. Maddocks M, Kon SS, Singh SJ, Man WD. Rehabilitation following hospitalization in patients with COPD: can it reduce readmissions? Respirology. 2015;20(3):395-404.

14. Puhan MA, Gimeno-Santos E, Scharplatz M, Troosters T, Walters EH, Steurer J. Pulmonary rehabilitation following exacerbations of chronic obstructive pulmonary disease. Cochrane Database Syst Rev. 2011; 10(CD005305).

15. Bolton CE, Bevan-Smith EF, Blakey JD, et al. British Thoracic Society guideline on pulmonary rehabilitation in adults. Thorax. 2013; 68 (Suppl 2):ii1-ii30.

16. Spruit MA, Pitta F, McAuley E, ZuWallack RL, Nici L. Pulmonary rehabilitation and physical activity in patients with chronic obstructive pulmonary disease. Am J Respir Crit Care Med. 2015;192(8):924-933.

17. Kruis AL, Smidt N, Assendelft WJ, et al. Integrated disease management interventions for patients with chronic obstructive pulmonary disease. Cochrane Database Syst Rev. 2013;(10):CD009437.

18. Seymour JM, Moore L, Jolley CJ, et al. Outpatient pulmonary rehabilitation following acute exacerbations of COPD. Thorax. 2010;65(5): 423-428.

19. Puhan MA, Spaar A, Frey M, et al. Early versus late pulmonary rehabilitation in chronic obstructive pulmonary disease patients with acute exacerbations: a randomized trial. Respiration. 2012;83(6):499-506.

20. Man WD, Polkey MI, Donaldson N, Gray BJ, Moxham J. Community pulmonary rehabilitation after hospitalisation for acute exacerbations of chronic obstructive pulmonary disease: randomised controlled study. BMJ. 2004;329(7476):1209.

21. Harrison SL, Goldstein R, Desveaux L, Tulloch V, Brooks D. Optimizing nonpharmacological management following an acute exacerbation of chronic obstructive pulmonary disease. Int J Chron Obstruct Pulmon Dis. 2014;9:1197-1205.

22. Le Polain de Waroux O, Maguire H, Moren A. The case-cohort design in outbreak investigations. Euro Surveill. 2012;17(25):pii:20202.

23. Celli BR, MacNee W; ATS/ERS Task Force. Standards for the diagnosis and treatment of patients with COPD: a summary of the ATS/ERS position paper. Eur Respir J. 2004;23(6):932-946.

24. Standardization of Spirometry, 1994 Update. American Thoracic Society. Am J Respir Crit Care Med. 1995;152(3):1107-1136.

25. Roca J, Sanchis J, Agusti-Vidal A, et al. Spirometric reference values from a Mediterranean population. Bull Eur Physiopathol Respir. 1986; 22(3):217-224.

26. Rodriguez-Roisin R. Toward a consensus definition for COPD exacerbations. Chest. 2000;117(5 Suppl 2):S398-S401.

27. Anthonisen NR, Manfreda J, Warren CP, Hershfield ES, Harding GK, Nelson NA. Antibiotic therapy in exacerbations of chronic obstructive pulmonary disease. Ann Intern Med. 1987;106(2):196-204.
28. Woodhead M, Blasi F, Ewig S, et al. Guidelines for the management of adult lower respiratory tract infections - full version. Clin Microbiol Infect. 2011;(17 Suppl 6):E1-E59.

29. Bott J, Blumenthal S, Buxton M, et al. Guidelines for the physiotherapy management of the adult, medical, spontaneously breathing patient. Thorax. 2009;64 (Suppl 1):i1-i52.

30. Behnke M, Jörres RA, Kirsten D, Magnussen H. Clinical benefits of a combined hospital and home-based exercise programme over 18 months in patients with severe COPD. Monaldi Arch chest Dis. 2003;59(1):44-51.

31. Behnke M, Taube C, Kirsten D, Lehnigk B, Jörres RA, Magnussen H. Home-based exercise is capable of preserving hospital-based improvements in severe chronic obstructive pulmonary disease. Respir Med. 2000;94(12):1184-1191

32. Murphy N, Bell C, Costello RW. Extending a home from hospital care programme for COPD exacerbations to include pulmonary rehabilitation. Respir Med. 2005;99(10):1297-1302.

33. Crapo RO, Casaburi R, Coates AL, et al. ATS statement: guidelines for the six-minute walk test. Am J Respir Crit Care Med. 2002;166(1): 111-117.

34. Ghanem M, Elaal EA, Mehany M, Tolba K. Home-based pulmonary rehabilitation program: effect on exercise tolerance and quality of life in chronic obstructive pulmonary disease patients. Ann Thorac Med. 2010;5(1):18-25.

35. Zainuldin R, Mackey MG, Alison JA. Optimal intensity and type of leg exercise training for people with chronic obstructive pulmonary disease. Cochrane Database Syst Rev. 2011;(11):CD008008.

36. Spruit MA, Gosselink R, Troosters T, De Paepe K, Decramer M. Resistance versus endurance training in patients with COPD and peripheral muscle weakness. Eur Respir J. 2002;19(6):1072-1078.

37. Greening NJ, Williams JEA, Hussain SF, et al. An early rehabilitation intervention to enhance recovery during hospital admission for an exacerbation of chronic respiratory disease: randomised controlled trial. BMJ. 2014;349:g4315

38. Boxall AM, Barclay L, Sayers A, Caplan GA. Managing chronic obstructive pulmonary disease in the community. A randomized controlled trial of home-based pulmonary rehabilitation for elderly housebound patients. J Cardiopulm Rehabil. 2005;25(6):378-385.

39. Eaton T, Young P, Fergusson W, et al. Does early pulmonary rehabilitation reduce acute health-care utilization in COPD patients admitted with an exacerbation? A randomized controlled study. Respirology. 2009;14(2):230-238.

40. Moore E, Palmer T, Newson DR, Majeed A, Quint JK, Soljak MA. Pulmonary rehabilitation as a mechanism to reduce hospitalizations for acute exacerbations of chronic obstructive pulmonary disease: a systematic review and meta-analysis. Chest. 2016;150(4):837-859.

41. van Ranst D, Stoop WA, Meijer JW, Otten HJ, van de Port IG. Reduction of exacerbation frequency in patients with COPD after participation in a comprehensive pulmonary rehabilitation program. Int J Chron Obstruct Pulmon Dis. 2014;9:1059-1067.

42. Puhan MA, Scharplatz M, Troosters T, Steurer J. Respiratory rehabilitation after acute exacerbation of COPD may reduce risk for readmission and mortality - a systematic review. Respir Res. 2005;6(1):54.

43. Ko FW, Ngai JC, Ng SS, et al. COPD care programme can reduce readmissions and in-patient bed days. Respir Med. 2014;108(12): 1771-1778.

44. Ko FWS, Cheung NK, Rainer TH, Lum C, Wong I, Hui DSC. Comprehensive care programme for patients with chronic obstructive pulmonary disease: a randomised controlled trial. Thorax. 2017;72(2):122-128.

45. Bourbeau J, Julien M, Maltais F, et al. Reduction of hospital utilization in patients with chronic obstructive pulmonary disease: a diseasespecific self-management intervention. Arch Intern Med. 2003;163(5): 585-591.

46. Dajczman E, Robitaille C, Ernst P, et al. Integrated interdisciplinary care for patients with chronic obstructive pulmonary disease reduces emergency department visits, admissions and costs: a quality assurance study. Can Respir J. 2013;20(5):351-356. 
47. Peytremann-Bridevaux I, Taffe P, Burnand B, Bridevaux PO, Puhan MA. Mortality of patients with COPD participating in chronic disease management programmes: a happy end? Thorax. 2014;69(9): $865-866$.

48. Jordan RE, Majothi S, Heneghan NR, et al. Supported self-management for patients with moderate to severe chronic obstructive pulmonary disease (COPD): an evidence synthesis and economic analysis. Health Technol Assess. 2015;19(36):1-516.

49. Smidth M, Christensen MB, Fenger-Grøn M, Olesen F, Vedsted P. The effect of an active implementation of a disease management programme for chronic obstructive pulmonary disease on healthcare utilization a cluster-randomised controlled trial. BMC Health Serv Res. 2013; 13(1):385.

50. Fan VS, Gaziano JM, Lew R, et al. A comprehensive care management program to prevent chronic obstructive pulmonary disease hospitalizations. Ann Intern Med. 2012;156(10):673-683.

51. Johnson-Warrington V, Rees K, Gelder C, Morgan MD, Singh SJ. Can a supported self-management program for COPD upon hospital discharge reduce readmissions? A randomized controlled trial. Int $J$ Chron Obstruct Pulmon Dis. 2016;11:1161-1169.

52. Majothi S, Jolly K, Heneghan NR, et al. Supported self-management for patients with COPD who have recently been discharged from hospital: a systematic review and meta-analysis. Int J Chron Obstruct Pulmon Dis. 2015;10:853-867.

53. Bischoff EWMA, Akkermans R, Bourbeau J, van Weel C, Vercoulen JH, Schermer TRJ. Comprehensive self management and routine monitoring in chronic obstructive pulmonary disease patients in general practice: randomised controlled trial. BMJ. 2012;345:e7642.
54. Saleh S, Larsen JP, Bergsåker-Aspøy J, Grundt H. Re-admissions to hospital and patient satisfaction among patients with chronic obstructive pulmonary disease after telemedicine video consultation - a retrospective pilot study. Multidiscip Respir Med. 2014;9(1):6.

55. Pinnock H, Hanley J, McCloughan L, et al. Effectiveness of telemonitoring integrated into existing clinical services on hospital admission for exacerbation of chronic obstructive pulmonary disease: researcher blind, multicentre, randomised controlled trial. BMJ. 2013;347:f6070.

56. Coultas D, Frederick J, Barnett B, Singh G, Wludyka P. A randomized trial of two types of nurse-assisted home care for patients with COPD. Chest. 2005;128(4):2017-2024.

57. Puhan MA, Mador MJ, Held U, Goldstein R, Guyatt GH, Schunemann HJ. Interpretation of treatment changes in 6-minute walk distance in patients with COPD. Eur Respir J. 2008;32(3):637-643.

58. Polkey MI, Spruit MA, Edwards LD, et al; Evaluation of COPD Longitudinally to Identify Predictive Surrogate Endpoints (ECLIPSE) Study Investigators. Six-minute-walk test in chronic obstructive pulmonary disease: minimum cinically important difference for death orhospitalization. Am J Respir Crit Care Med. 2013;187(4):382-386.

59. Jones SE, Green SA, Clark AL, et al. Pulmonary rehabilitation following hospitalisation for acute exacerbation of COPD: referrals, uptake and adherence. Thorax. 2014;69(2):181-182.

60. Harrison SL, Robertson N, Graham CD, et al. Can we identify patients with different illness schema following an acute exacerbation of COPD: a cluster analysis. Respir Med. 2014;108(2):319-328.

61. Luk EK, Hutchinson AF, Tacey M, Irving L, Khan F. COPD: health care utilisation patterns with different disease management interventions. Lung. Epub 2017 May 4.
International Journal of COPD

\section{Publish your work in this journal}

The International Journal of COPD is an international, peer-reviewed journal of therapeutics and pharmacology focusing on concise rapid reporting of clinical studies and reviews in COPD. Special focus is given to the pathophysiological processes underlying the disease, intervention programs, patient focused education, and self management protocols.

\section{Dovepress}

This journal is indexed on PubMed Central, MedLine and CAS. The manuscript management system is completely online and includes a very quick and fair peer-review system, which is all easy to use. Visit $\mathrm{http}: / /$ www.dovepress.com/testimonials.php to read real quotes from published authors. 